\title{
Novel Strategy to Fabricate Floating Drug Delivery System Based on Sublimation Technique
}

\author{
Kampanart Huanbutta, ${ }^{1,2}$ Sontaya Limmatvapirat, ${ }^{2,3}$ Srisagul Sungthongjeen, ${ }^{4}$ and Pornsak Sriamornsak ${ }^{2,3,5}$
}

Received 6 May 2015; accepted 18 August 2015; published online 28 August 2015

\begin{abstract}
The present study aims to develop floating drug delivery system by sublimation of ammonium carbonate (AMC). The core tablets contain a model drug, hydrochlorothiazide, and various levels (i.e., 0 $50 \% w / w)$ of AMC. The tablets were then coated with different amounts of the polyacrylate polymers (i.e., Eudragit ${ }^{\circledR}$ RL100, Eudragit ${ }^{\circledR}$ RS100, and the mixture of Eudragit $₫$ RL100 and Eudragit ${ }^{\circledR}$ RS100 at 1:1 ratio). The coated tablets were kept at ambient temperature $\left(25^{\circ} \mathrm{C}\right)$ or cured at $70^{\circ} \mathrm{C}$ for $12 \mathrm{~h}$ before further investigation. The floating and drug release behaviors of the tablets were performed in simulated gastric fluid USP without pepsin at $37^{\circ} \mathrm{C}$. The results showed that high amount of AMC induced the floating of the tablets. The coated tablets containing 40 and 50\% AMC floated longer than $8 \mathrm{~h}$ with a timeto-float of about $3 \mathrm{~min}$. The sublimation of AMC from the core tablets decreased the density of system, causing floating of the tablets. The tablets coated with Eudragit ${ }^{\circledR}$ RL100 floated at a faster rate than those of Eudragit ${ }^{\circledR}$ RS100. Even the coating level of polymer did not influence the time-to-float and floating time of coated tablets containing the same amount of AMC, the drug release from the tablets coated with higher coating level of polymer showed slower drug release. The results suggested that the sublimation technique using AMC is promising for the development of floating drug delivery system.
\end{abstract}

KEY WORDS: floating tablets; gas formation; gastroretentive drug delivery system; sublimation technique; sustained release.

\section{INTRODUCTION}

Gastroretentive dosage forms, which are designed to exhibit a prolonged gastric residence time, have been a topic of interest in terms of their potential for controlled drug delivery. The dosage forms are particularly appropriate for drugs that are unstable in the intestine or colonic environment, drugs with low solubility at high $\mathrm{pH}$ values or with an absorption window in stomach or upper small intestine, or drugs acting locally in the stomach, e.g., antibiotic administration for Helicobacter pylori eradication in the treatment of peptic ulcer (1). Over the last few decades, several gastroretentive drug delivery approaches are being designed and developed, including high-density (sinking) systems that is retained in the bottom of the stomach, low-density (floating) systems that causes buoyancy in gastric fluid, mucoadhesive systems that causes bioadhesion to mucin-epithelial surface of stomach,

\footnotetext{
${ }^{1}$ Faculty of Pharmaceutical Science, Burapha University, Chonburi, 20131, Thailand.

${ }^{2}$ Pharmaceutical Biopolymer Group (PBiG), Faculty of Pharmacy, Silpakorn University, Nakhon Pathom, 73000, Thailand.

${ }^{3}$ Department of Pharmaceutical Technology, Faculty of Pharmacy, Silpakorn University, Nakhon Pathom, 73000, Thailand.

${ }^{4}$ Department of Pharmaceutical Technology, Faculty of Pharmaceutical Sciences, Naresuan University, Phitsanulok, 65000, Thailand.

${ }^{5}$ To whom correspondence should be addressed. (e-mail: pornsak@su.ac.th)
}

swellable systems which limits emptying of the dosage forms through the pyloric sphincter of stomach, etc. (2).

Various attempts have been made to develop a floating system that could prolong gastric residence time, thereby targeting site-specific drug release in the upper gastrointestinal tract for local or systemic effects. The system basically floats in the gastric fluid because of its lower bulk density compared to that of the aqueous medium (3). Several approaches have been applied to levitate the drug delivery system, such as gas-generating, gas-filled floatation, and raftforming systems (4). However, there are some limitations from the available floating mechanisms; for example, the gas-generating mechanism takes time for floating. Besides, the preparation process of the pre-gas-filled system is complicated (5). Consequently, a novel and non-complicated technique offering short floating time is a crucial point to develop. Oh et al. (6) prepared highly porous gastroretentive metformin tablets from sublimation technique by using camphor as a sublimation material. They found that the prepared floating gastroretentive tablets floated for over $24 \mathrm{~h}$ and had no floating lag time. However, as the amount of camphor in the tablet matrix increased, the crushing strength of the tablet decreased after sublimation. However, the sublimation technique is simple to fabricate and system can float instantaneously. Furthermore, this technique also shows possibility in industrial production scale due to the use of a few simple preparation steps and affordable pharmaceutical excipients. 
Table I. Formulation of Core Tablets

\begin{tabular}{lllll}
\hline Component $(\% w / w)$ & AMC0 & AMC20 & AMC40 & AMC50 \\
\hline HCTZ & 10 & 10 & 10 & 10 \\
MCC & 86.5 & 66.5 & 46.5 & 36.5 \\
AMC & 0 & 20 & 40 & 50 \\
PVP K30 & 3 & 3 & 3 & 3 \\
Magnesium stearate & 0.5 & 0.5 & 0.5 & 0.5 \\
\hline
\end{tabular}

Therefore, the aim of this research was to develop a floating drug delivery system prepared by sublimation technique, i.e., tablets containing ammonium carbonate (AMC; $\left.\left(\mathrm{NH}_{4}\right)_{2} \mathrm{CO}_{3}\right)$ that can form gas or sublime at high temperature, and then coated with polyacylate polymers to prolong the floating and sustain the drug release. The developed system was compared with that prepared by gas formation technique. The effects of level of AMC (i.e., 0-50\% w/w), type of polyacrylate polymers, and coating level on floating and drug release behaviors were also investigated.

\section{MATERIALS AND METHODS}

\section{Materials}

Hydrochlorothiazide (HCTZ) was purchased from Sigma-Aldrich (Steinheim, Germany). Ammonium carbonate (AMC) was purchased from Riedel-de Haen (Seelze, Germany). Eudragit ${ }^{\circ}$ RS100 (referred to as RS100) and Eudragit ${ }^{\circ}$ RL100 (referred to as RL100) were kindly donated by JJ Degussa Chemical (Thailand) Ltd., Bangkok, Thailand. Microcrystalline cellulose (MCC; Avicel PH101) was obtained from FMC (Philadelphia, USA). Polyvinylpyrrolidone K30 (PVP K30) was obtained from BASF (Thai) Co., Ltd. (Bangkok, Thailand). All other chemicals were of reagent grade or pharmaceutical grade and used without further purification.

\section{Preparation of Core Tablets}

The core tablets containing a model drug, HCTZ, were prepared by wet granulation method. Various amounts of AMC (i.e., $0-50 \% w / w$ ) were incorporated in the core tablets (Table I). The core tablets were compressed in concave shape using a single-punch tableting machine (Yeo Heng, Thailand). Profile of the core tablets including weight, thickness, diameter, crushing strength, and tablet surface area were monitored to control tablet properties.

Table II. Formulation of Coating Solution

\begin{tabular}{lllc}
\hline Component $(\% w / w)$ & RL100 & RS100 & $\begin{array}{c}\text { RL100: RS100 } \\
(1: 1)\end{array}$ \\
\hline Eudragit@ RL100 & & & 3.75 \\
Eudragit@ RS100 & 7.50 & 7.50 & 3.75 \\
Dibutyl sebacate & - & - & 1.50 \\
Talcum & 1.50 & 1.50 & 0.30 \\
Color & 0.30 & 0.30 & 0.01 \\
Organic solvent; $\quad 0.01$ & 0.01 & 90.69 \\
$\quad$ IPA:acetone: $\mathrm{CH}_{2} \mathrm{Cl}_{2}(2: 1: 1)$ & & 90.69 & \\
\hline
\end{tabular}

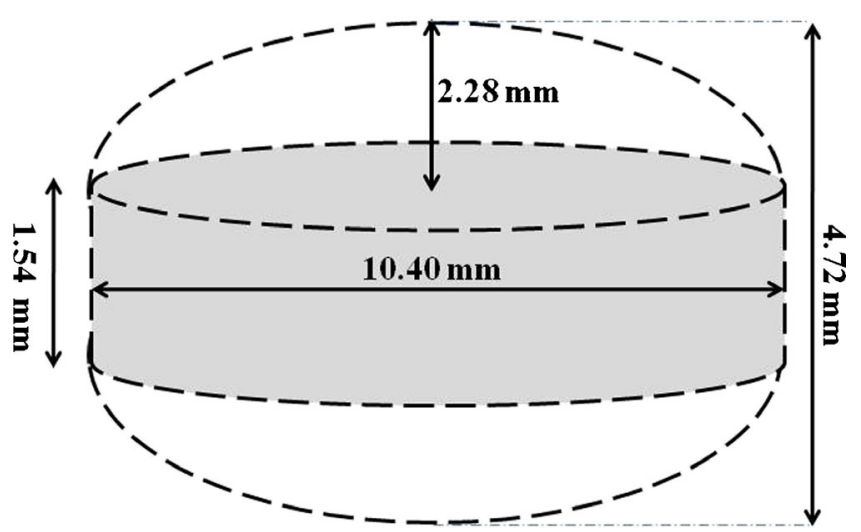

Fig. 1. Dimension of the core tablet

\section{Preparation of Coated Tablets}

The core tablets were coated with different types of polyacylate polymers, that is, RL100, RS100, and a mixture of RL100 and RS100 at ratio of 1:1 as presented in Table II. The coating solution was sprayed onto the core tablets in a perforated pan coater (model RamaCota 18, Narongkarnchang, Thailand) under the following conditions: flow rate of coating solution, $10 \mathrm{~mL} / \mathrm{min}$; inlet air temperature, $60^{\circ} \mathrm{C}$; outlet air temperature, $50^{\circ} \mathrm{C}$; pressure, 2 bars; and pan speed, $12 \mathrm{rpm}$. To observe the effect of film thickness, two coating levels $\left(2.71\right.$ and $\left.4.89 \mathrm{mg} / \mathrm{cm}^{2}\right)$ were applied. The coated tablets were kept at either ambient temperature $\left(25^{\circ} \mathrm{C}\right)$ or cured at $70^{\circ} \mathrm{C}$ for $12 \mathrm{~h}$ before further investigation. The properties of the coated tablets such as thickness of film and tablet, weight, diameter, tablet density, and residual amount of ammonia were evaluated.

\section{Differential Scanning Calorimetry}

To monitor drug-excipient interaction, the differential scanning calorimetry (DSC) thermograms of the starting materials (HCTZ, AMC, and MCC) and the mixtures between the model drug (HCTZ) and each major excipient (AMC and $\mathrm{MCC}$ ) at ratio of 1:1 were determined by differential scanning calorimeter (Sapphire, PerkinElmer, USA) using indium as a<smiles>[R20]C(=O)C([R1])(C)CC(C)(CC)C(=O)OCC[N+](C)(C)C</smiles>

Fig. 2. Chemical structure of Eudragit ${ }^{\circ}$ RS100 and RL100 
Table III. Weight, Time-to-Float, and Floating Time of the Coated Tablets

\begin{tabular}{|c|c|c|c|c|c|c|c|c|}
\hline \multirow[t]{2}{*}{ Coating solution } & \multirow{2}{*}{$\begin{array}{c}\text { Coating } \\
\text { level }\end{array}$} & \multirow[t]{2}{*}{ AMC amount } & \multicolumn{2}{|c|}{ Weight (mg) } & \multicolumn{2}{|c|}{ Time-to-float (min) } & \multicolumn{2}{|c|}{ Floating time (h) } \\
\hline & & & Non-cured & $\begin{array}{l}\text { Cured } \\
\text { at } 70^{\circ} \mathrm{C}\end{array}$ & Non-cured & $\begin{array}{l}\text { Cured } \\
\text { at } 70^{\circ} \mathrm{C}\end{array}$ & $\begin{array}{l}\text { Non- } \\
\text { cured }\end{array}$ & $\begin{array}{l}\text { Cured } \\
\text { at } 70^{\circ} \mathrm{C}\end{array}$ \\
\hline \multirow[t]{8}{*}{ RS100 } & \multirow[t]{4}{*}{$4.89 \mathrm{mg} / \mathrm{cm}^{2}$} & $\mathrm{AMC0}$ & $416.0 \pm 6.3$ & $396.8 \pm 4.3$ & Not float & Not float & Not float & Not float \\
\hline & & AMC20 & $394.9 \pm 4.2$ & $360.4 \pm 9.2$ & $4.5 \pm 2.0$ & Not float & $>8$ & Not float \\
\hline & & AMC40 & $368.2 \pm 8.4$ & $294.5 \pm 12.4$ & $2.6 \pm 2.3$ & Immediately & $>8$ & $>8$ \\
\hline & & AMC50 & $375.8 \pm 7.5$ & $267.93 \pm 4.41$ & $2.5 \pm 1.3$ & Immediately & $>8$ & $>8$ \\
\hline & \multirow[t]{4}{*}{$2.71 \mathrm{mg} / \mathrm{cm}^{2}$} & AMC0 & $417.3 \pm 10.9$ & $397.6 \pm 9.7$ & Not float & Not float & Not float & Not float \\
\hline & & AMC20 & $400.2 \pm 9.7$ & $365.9 \pm 7.7$ & $3.1 \pm 2.6$ & Not float & $>8$ & Not float \\
\hline & & AMC40 & $365.6 \pm 8.2$ & $295.5 \pm 7.3$ & $2.5 \pm 2.2$ & Immediately & $>8$ & $>8$ \\
\hline & & AMC50 & $369.5 \pm 7.3$ & $266.3 \pm 8.3$ & $2.1 \pm 1.2$ & Immediately & $>8$ & $>8$ \\
\hline \multirow[t]{8}{*}{ RL100 } & \multirow[t]{4}{*}{$4.89 \mathrm{mg} / \mathrm{cm}^{2}$} & $\mathrm{AMC0}$ & $414.0 \pm 6.3$ & $392.0 \pm 3.6$ & Not float & Not float & Not float & Not float \\
\hline & & AMC20 & $379.6 \pm 8.3$ & $345.7 \pm 14.7$ & $1.8 \pm 2.7$ & $0.42+0.54$ & $>8$ & $>8$ \\
\hline & & AMC40 & $356.7 \pm 11.8$ & $299.9 \pm 15.3$ & $2.2 \pm 2.3$ & Immediately & $>8$ & $>8$ \\
\hline & & AMC50 & $340.1 \pm 14.4$ & $259.6 \pm 12.5$ & $1.4 \pm 3.4$ & Immediately & $>8$ & $>8$ \\
\hline & \multirow[t]{4}{*}{$2.71 \mathrm{mg} / \mathrm{cm}^{2}$} & $\mathrm{AMCO}$ & $410.0 \pm 5.1$ & $389.6 \pm 4.3$ & Not float & Not float & Not float & Not float \\
\hline & & AMC20 & $373.5 \pm 11.7$ & $341.3 \pm 13.6$ & $1.5 \pm 1.4$ & $0.12+0.18$ & $>8$ & $>8$ \\
\hline & & AMC40 & $352.7 \pm 14.1$ & $301.2 \pm 18.5$ & $2.5 \pm 3.2$ & Immediately & $>8$ & $>8$ \\
\hline & & AMC50 & $346.1 \pm 18.2$ & $258.6 \pm 14.6$ & $1.1 \pm 4.5$ & Immediately & $>8$ & $>8$ \\
\hline \multirow{8}{*}{$\begin{array}{l}\text { RS100: } \\
\quad \text { RL100 (1:1) }\end{array}$} & \multirow[t]{4}{*}{$4.89 \mathrm{mg} / \mathrm{cm}^{2}$} & $\mathrm{AMCO}$ & $419.0 \pm 6.0$ & $396.9 \pm 5.4$ & Not float & Not float & Not float & Not float \\
\hline & & AMC20 & $385.8 \pm 8.6$ & $360.0 \pm 10.4$ & $4.5 \pm 2.0$ & Not float & $>8$ & Not float \\
\hline & & AMC40 & $373.4 \pm 11.5$ & $294.5 \pm 13.1$ & $2.6 \pm 2.3$ & Immediately & $>8$ & $>8$ \\
\hline & & AMC50 & $385.3 \pm 8.3$ & $267.9 \pm 6.3$ & $2.5 \pm 1.3$ & Immediately & $>8$ & $>8$ \\
\hline & \multirow[t]{4}{*}{$2.71 \mathrm{mg} / \mathrm{cm}^{2}$} & $\mathrm{AMCO}$ & $418.8 \pm 5.5$ & $397.7 \pm 4.2$ & Not float & Not float & Not float & Not float \\
\hline & & AMC20 & $390.5 \pm 7.1$ & $365.7 \pm 9.3$ & $3.2 \pm 2.6$ & Not float & $>8$ & Not float \\
\hline & & AMC40 & $375.2 \pm 9.6$ & $298.8 \pm 11.3$ & $2.5 \pm 2.2$ & Immediately & $>8$ & $>8$ \\
\hline & & AMC50 & $390.5 \pm 5.3$ & $270.8 \pm 7.8$ & $2.1 \pm 1.2$ & Immediately & $>8$ & $>8$ \\
\hline
\end{tabular}

standard. About 2-3 mg sample was accurately weighed and placed in a closed aluminum solid pan. The aluminum pan was then transferred into the furnace. The thermal characteristic of sample was determined at heating rate of $10^{\circ} \mathrm{C} / \mathrm{min}$ from 25 to $290^{\circ} \mathrm{C}$ using an empty closed aluminum solid pan as a reference. The measurement was done under nitrogen purge at a flow rate of $10 \mathrm{~mL} / \mathrm{min}$.

\section{Floating Properties}

The floating properties of the coated tablets, such as floating time and time-to-float, were monitored in the closed medium-filled flask placed in a horizontal shaker (model OS1473VBA, Revco Scientific Inc., USA) at $37^{\circ} \mathrm{C}$ (7) using $70 \mathrm{~mL}$ of simulated gastric fluid USP without pepsin (SGF) as a medium. Ten floating tablets were placed in the medium, and the floating properties were determined by visual observation.

\section{In Vitro Drug Release Studies}

HCTZ release from the coated tablets was investigated using USP dissolution apparatus I equipped with baskets, which were operated at a speed of $100 \mathrm{rpm}$. Nine hundred milliliters of SGF, as the dissolution medium, were placed in the glass vessel, the apparatus assembled, and the dissolution medium was equilibrated to $37 \pm 0.5^{\circ} \mathrm{C}$. The samples $(5 \mathrm{~mL})$ were taken at various time intervals, i.e., 10, 20, 30, 45, 60, 90, $120,150,180,240,300,360,420$, and $480 \mathrm{~min}$. Then, the amount of HCTZ released was measured by UV-vis spectrophotometer (model Lambda 2, PerkinElmer, USA) at maximum wavelength of $271 \mathrm{~nm}$. Each in vitro release study was performed in triplicate.

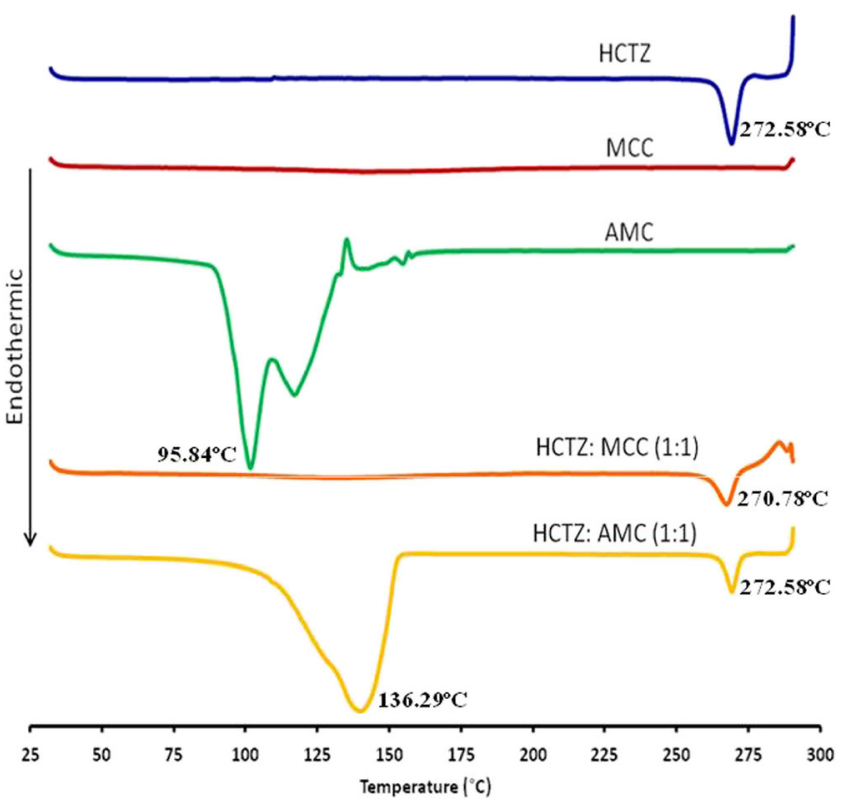

Fig. 3. DSC thermograms of the major materials (HCTZ, AMC, and MCC) and the mixtures between HCTZ and each excipient (AMC and MCC) at a ratio of $1: 1$ 


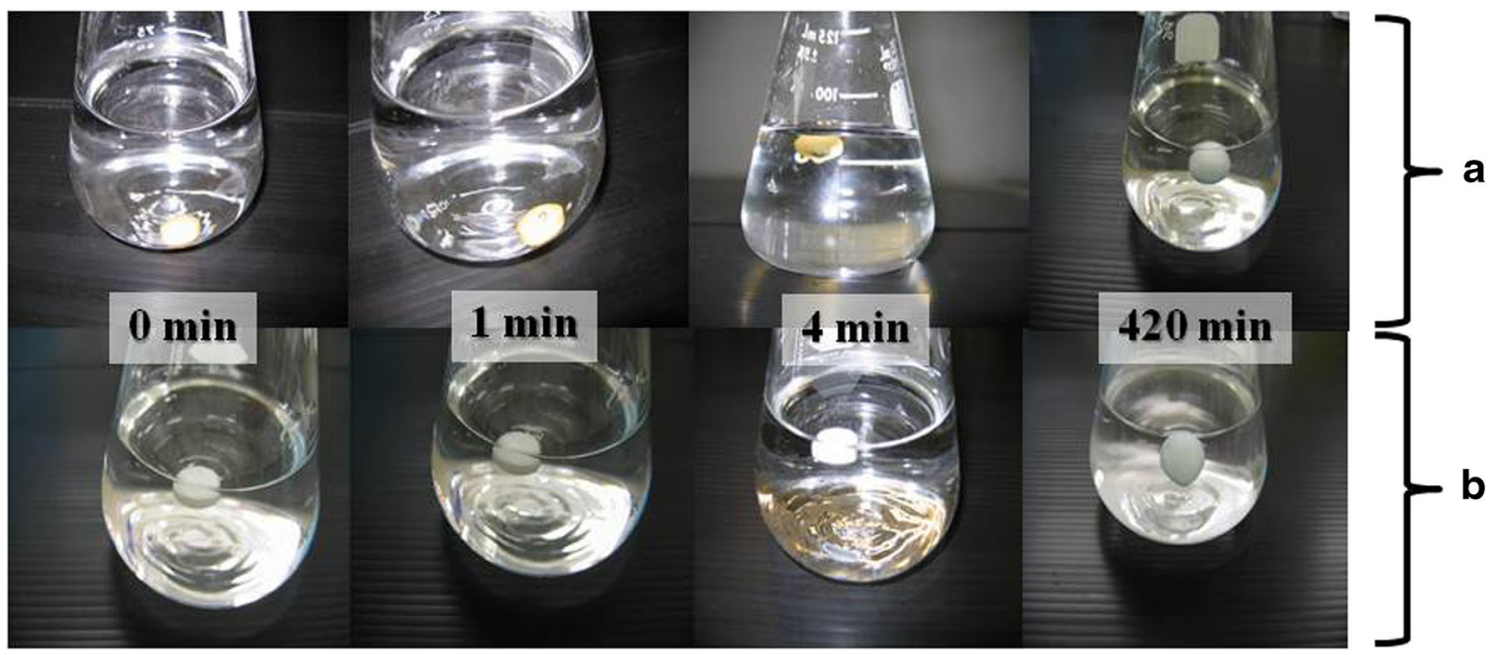

Fig. 4. Floating sequence in SGF ( $\mathrm{pH}$ 1.2) of the floating tablets a after keeping at ambient temperature, and $\mathbf{b}$ after curing at $70^{\circ} \mathrm{C}$ for $12 \mathrm{~h}$

\section{Statistical Analysis}

Analysis of variance (ANOVA) and Levene's test for homogeneity of variance were performed using SPSS version 10.0 for Windows (SPSS Inc., USA). Post hoc testing $(p<0.05)$ of the multiple comparisons was performed by either the Scheffé or Games-Howell test depending on whether Levene's test was insignificant or significant, respectively.

\section{RESULTS AND DISCUSSION}

\section{Fabrication of Floating Tablets}

The core tablets containing HCTZ and AMC at different ratios were prepared by wet granulation method. The weight of core tablets was uniform $(4.72 \pm 0.07 \mathrm{~g})$. The dimension of core tablet is shown in Fig. 1. The percentage of friability was
Kept at ambient temperature $\left(25^{\circ} \mathrm{C}\right)$

Cured at $70^{\circ} \mathrm{C}$ for $12 \mathrm{~h}$
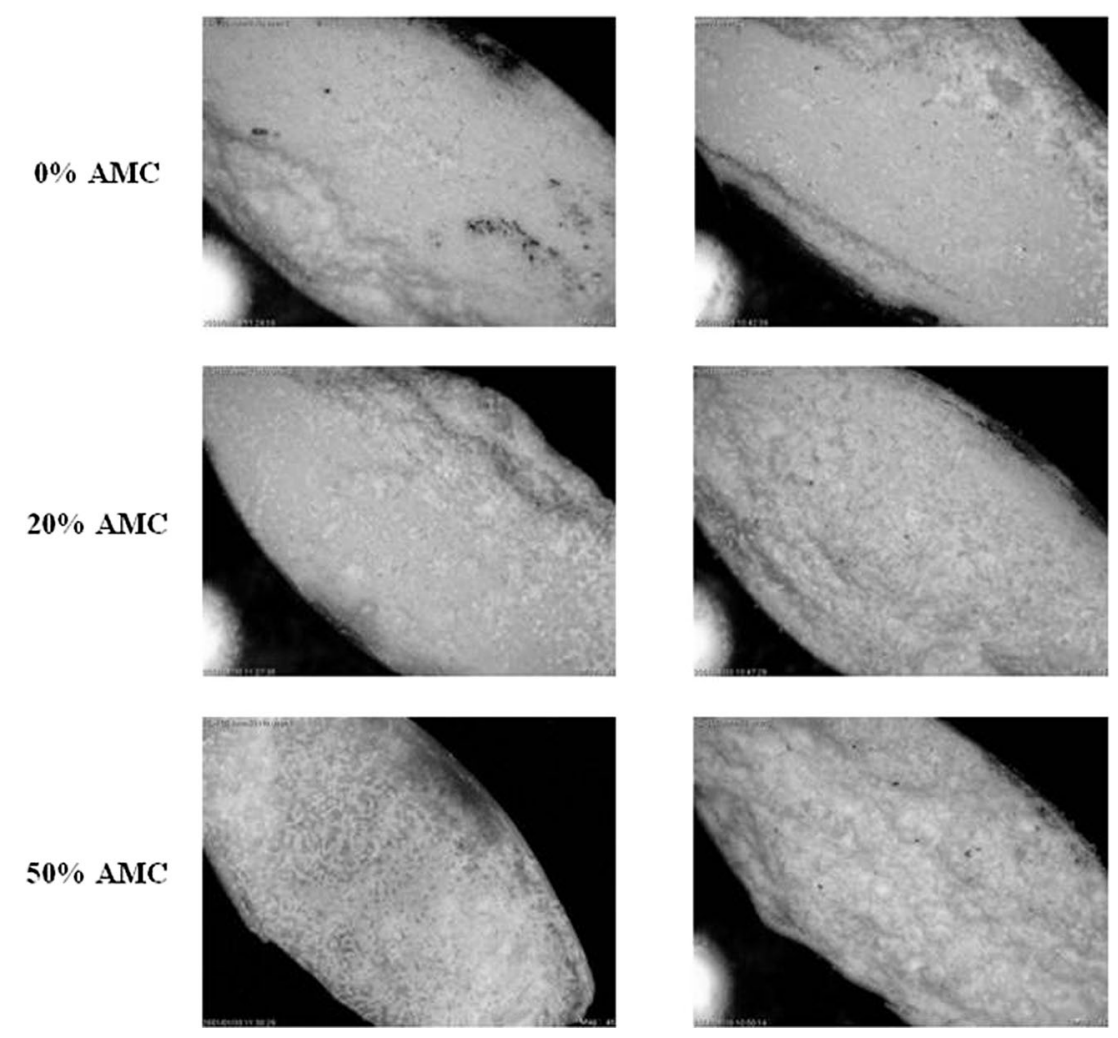

Fig. 5. Cross-section images of the coated tablet kept at ambient temperature and cured at $70^{\circ} \mathrm{C}$ for $12 \mathrm{~h}$, with different amounts of AMC 


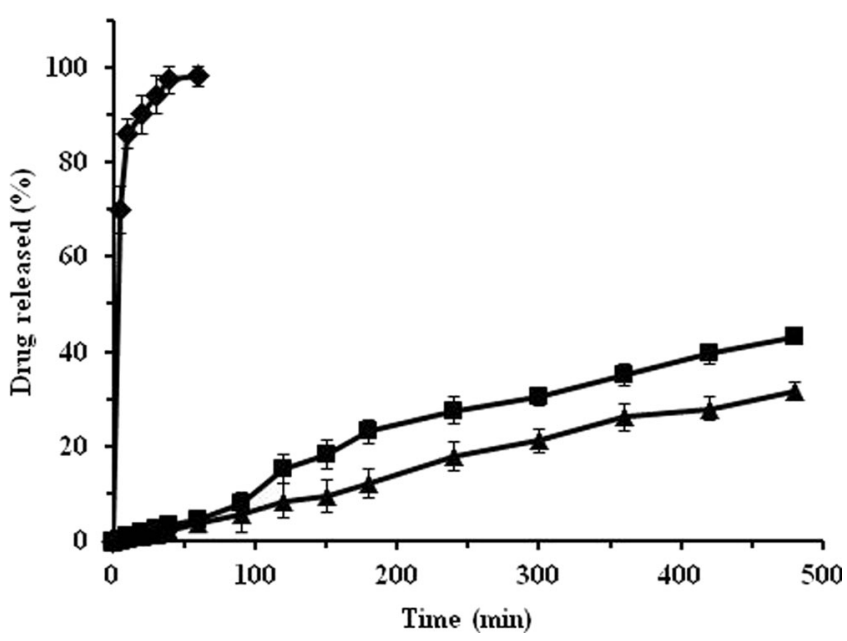

Fig. 6. Drug release profiles of core tablets (AMC40) (black diamond) and AMC40 tablets coated with RL100 at coating level of $2.71 \mathrm{mg} / \mathrm{cm}^{2}$ (black square) and $4.89 \mathrm{mg} / \mathrm{cm}^{2}$ (black triangle)

$0.072 \%$, and the surface area of the core tablet was calculated to be $207.67 \pm 0.96 \mathrm{~mm}^{2}$. The crushing strength of core tablets was around $0.98-1.12 \mathrm{~N} / \mathrm{mm}^{2}$ while that of coated tablets was between 1.26 and $1.40 \mathrm{~N} / \mathrm{mm}^{2}$. The coated tablets cured at $70^{\circ} \mathrm{C}$ provided lower crushing strength $\left(0.56-1.12 \mathrm{~N} / \mathrm{mm}^{2}\right)$ than the coated tablets before curing.

The core tablets were coated with polyacrylate polymers, i.e., RL100 and/or RS100 (Fig. 2). These polymers have been reported to be a good candidate for gas-entrapped membrane for floating tablets (7). Basically, RL100 and RS100 are copolymer of ethyl acrylate, methyl methacrylate, and a low content of methacrylic acid ester with quaternary ammonium groups. The ammonium groups are present as salts and make the polymers permeable. The molar ratio of ethyl acrylate, methyl methacrylate, and trimethylammonioethyl methacrylate is approximately 1:2:0.2 for RL100 and 1:2:0.1 for RS100. Therefore, the RL100 offers higher permeability than that of RS100 (8). The high water permeability may be the ideal property for gas-entrapped floating dosage forms, in order to facilitate the floating process. After coating, regardless of curing process, the tablet weight of coated tablets containing

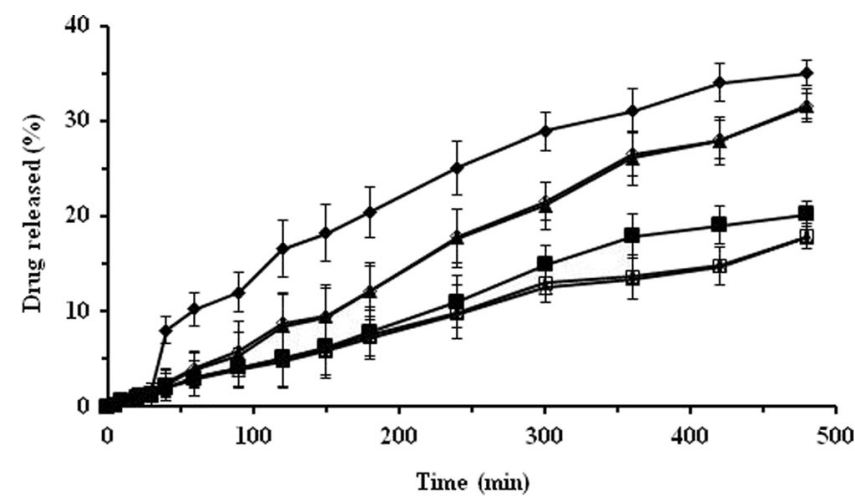

Fig. 7. Drug release profiles of floating tablets, cured at $70^{\circ} \mathrm{C}$, containing AMC20 (white square), AMC40 (white triangle), and AMC50 (white diamond), and non-cured tablets containing AMC20 (black square), AMC40 (black triangle), and AMC50 (black diamond) that coated with RS100 at coating level of $4.89 \mathrm{mg} / \mathrm{cm}^{2}$
AMC decreased, compared to the tablets with no AMC (Table III). The decrease of tablet weight was more pronounced after curing at $70^{\circ} \mathrm{C}$, suggesting a sublimation of AMC during heating. The weight of tablets coated with RL100, RS100, or RL100/RS100, at the same ratio of AMC, was not significantly different.

\section{Differential Scanning Calorimetry}

DSC study was conducted to monitor interaction between drug and major excipients in the tablets. Figure 3 shows the DSC thermograms of the major materials (HCTZ, AMC, and MCC) and the mixtures between HCTZ and each excipient (AMC and MCC) at ratio of 1:1. The thermogram of HCTZ exhibited an exotherm at $272.6^{\circ} \mathrm{C}$, which is the melting point of HCTZ (9). MCC did not express any sharp peak due to its amorphous property. AMC offered endothermic peaks at 95.8 and $115.1^{\circ} \mathrm{C}$ as reported in the previous study (10). The characteristic endothermic peak of HCTZ around $272^{\circ} \mathrm{C}$ still existed in the DSC thermograms of the binary mixtures of HCTZ with each major excipient, at 1:1 ratio. These can conclude that there is no interaction between the model drug and the tablet excipients (9).

\section{Floating Properties}

Table III also demonstrates time-to-float and floating time of the coated tablets. The results showed that high amount of AMC induced the floating of the tablets. The uncoated tablets containing $40-50 \%$ AMC could float in a few minutes due to carbon dioxide produced from the reaction of AMC with the acidic medium. However, the floating time was quite short as the tablets disintegrated or eroded during the test (data not shown). It could be because density of the uncoated tablet were lower than that of the acidic medium making the tablet floating. After that, the medium gradually penetrated into the uncoated porous tablets, resulting in drowning. From Table III, three factors play a vital role on the floating behavior, i.e., the amount of AMC, type of coating polymer, and tablet curing. The coated tablets do not float without AMC. The curing process could significantly reduce time-to-float, compared to non-cured ones.

As illustrated in Fig. 4, the coated tablets of AMC40 and AMC50 cured at $70^{\circ} \mathrm{C}$ floated immediately with a floating time longer than $8 \mathrm{~h}$ while the non-cured tablets with 20$50 \%$ AMC took about $1.12-4.54 \mathrm{~min}$ before floating. It is obvious that the higher amount of AMC provided shorter time-to-float. This is because AMC sublimated after curing at $70^{\circ} \mathrm{C}$ or produced gas after immersing in acid medium, making their total density lower than the SGF.

Figure 5 demonstrates cross-section images of the coated tablet kept at ambient temperature and cured at $70^{\circ} \mathrm{C}$ for $12 \mathrm{~h}$, with different amounts of AMC. It could be seen that the tablets containing 40-50\% AMC were more porous after curing at $70^{\circ} \mathrm{C}$ for $12 \mathrm{~h}$. This influenced the floating properties of the cured tablets, i.e., the cured tablets floated immediately while the non-cured tablets required time for effervescence reaction of AMC to occur in acid medium. Furthermore, high amount of AMC could produce a highly porous tablet, resulting in a shorter time-to-float. It is possible to conclude that the floating mechanism of cured and non-cured coated 


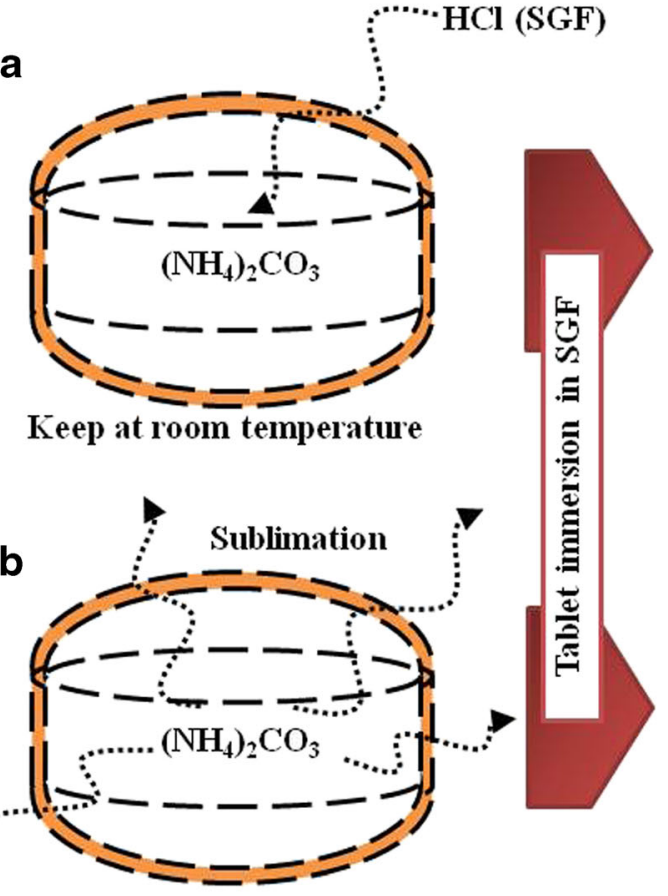

Tablet curing at $70^{\circ} \mathrm{C}$ for $12 \mathrm{~h}$
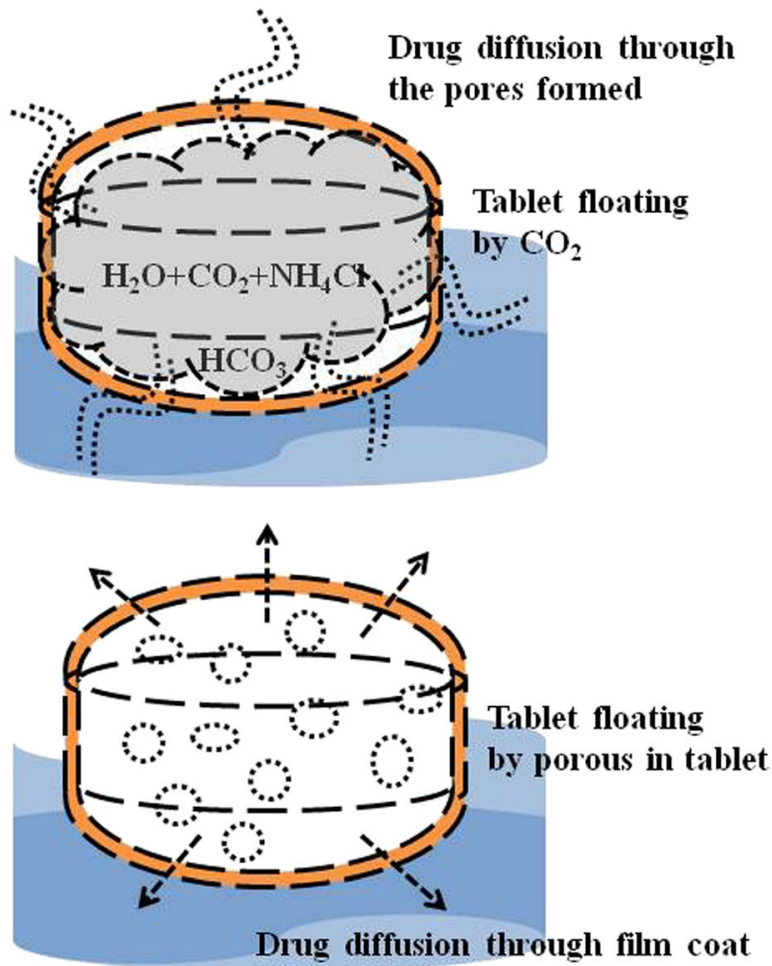

Fig. 8. Proposed floating and drug release mechanisms of a the non-cured floating tablets, containing AMC and $\mathbf{b}$ the floating tablets containing $\mathrm{AMC}$, cured at $70^{\circ} \mathrm{C}$

tablets was based on their porous structure and gas formation, respectively.

The coating level of polymer did not influence the timeto-float and floating time of coated tablets, at the same level of AMC (Table III). However, the type of the coating polymers affected the floating behavior. For non-cured floating tablets, the tablets floated faster when coated with RL100, compared to that coated with RS100. This is probably because solubility of RL100 is higher than that of RS100, causing a higher water permeability of RL100 film (11). Consequently, the SGF can expediently diffuse through the RL100 film to interact with AMC and generate gas, in a faster rate than that of RS100.

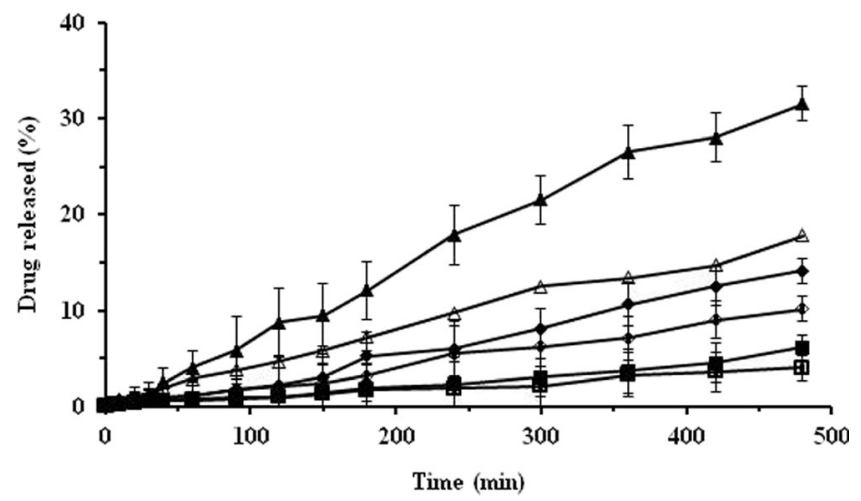

Fig. 9. Drug release profiles of the floating tablets, cured at $70^{\circ} \mathrm{C}$, containing 40\% AMC (open symbol) and 50\% AMC (close symbol). The tablets were coated with RS100 (square), RL100 (triangle), and the mixture of RS100 and RL100 at ratio of 1:1 (diamond), at coating level of $4.89 \mathrm{mg} / \mathrm{cm}^{2}$

\section{In Vitro Drug Release Studies}

Though the coating level of polymer did not influence the time-to-float and floating time of the coated tablets, at the same level of AMC (Table III), the drug release from the tablets coated with higher level of coating polymer showed a slower drug release. As illustrated in Fig. 6, drug release from tablets coated with $2.71 \mathrm{mg} / \mathrm{cm}^{2}$ of polymer film was significantly faster than that coated with $4.89 \mathrm{mg} / \mathrm{cm}^{2}$ of polymer film. The results agreed with the previous report (12) that the thicker film coat extends drug diffusion distance and subsequently slows the drug release.

Drug release profiles of the coated tablets containing different amounts of AMC are shown in Fig. 7. It could be clearly seen that higher amount of AMC enhanced drug release in the non-cured floating tablets. Figure 8a demonstrated the proposed floating and drug release mechanism of the non-cured floating tablets containing AMC. The polymeric film permitted dissolution medium to induce the effervescent generated sufficient amount of carbon dioxide $\left(\mathrm{CO}_{2}\right)$ to make the tablets float. The produced $\mathrm{CO}_{2}$ resulted in the swelling of coated tablets according to a gas pressure and subsequently drug release.

For the floating tablets cured at $70^{\circ} \mathrm{C}$, drug release was significantly slower than that of non-cured tablets. It is likely that the curing effect by heat helped to strengthen the coated film, resulting in a slower drug release caused by a dense film. Moreover, drug release from the cured floating tablets was not significantly different between those containing AMC20 and AMC40. This finding agreed with a previous study that noncured tablets containing high amount of gas-forming agent provided a faster drug release (7) as the AMC reacted with 
SGF, resulting in ammonium chloride $\left(\mathrm{NH}_{4} \mathrm{Cl}\right)$ and $\mathrm{CO}_{2}$. Figure $8 \mathrm{~b}$ demonstrated the floating and drug release mechanism of the floating tablets cured at $70^{\circ} \mathrm{C}$, i.e., the sublimation of AMC occurred during heating, causing porosity inside the tablets. In addition, the amount of AMC played a vital role on drug release. Using higher amount of AMC (i.e., 50\% AMC) provided a higher drug release, compared to that using lower level of AMC (i.e., 20 or $40 \% \mathrm{AMC})$. It is possible that higher amount of AMC can produce porous tablets of greater porosity, inducing higher permeation of the dissolution medium and resulting in higher drug release $(13,14)$.

Figure 9 reveals the effect of type of the coating polymer (RS100, RL100, and mixture of RS100 and RL100 at the ratio of $1: 1)$ on the drug release of the floating tablets cured at $70^{\circ} \mathrm{C}$. The results demonstrated that drug release from RL100 was faster than the mixture and RS100, respectively. This result is consistent with the previous study (15) in that higher hydrophilic portion, trimethylammonioethyl methacrylate group, in RL100 increases solubility and accessibility of the medium through the membrane, resulting in a significant higher drug release.

\section{CONCLUSION}

The floating properties and drug release from the floating tablets were dependent on the amount of AMC, levels, and types of coating polymer. The optimum formulation and conditions for this system is the tablets containing 40\% AMC, which was coated with RL100 at coating level of $2.71 \mathrm{mg} / \mathrm{cm}^{2}$ and cured at $70^{\circ} \mathrm{C}$. The tablets prepared from optimum formulation and conditions could float immediately with a floating time longer than $8 \mathrm{~h}$, and the drug release was rarely interfered by the coating system. The results suggested that either the gas formation or sublimation technique using AMC is promising for the development of floating drug delivery system.

\section{ACKNOWLEDGMENTS}

The authors acknowledge Silpakorn University Research and Development Institute for financial support. The laboratory assistance by Mr. Kongdetch Prasannam and Ms. Kamonrak Cheewatanakornkool is greatly appreciated. Thanks also to JJ Degussa Chemical (Thailand) who kindly provided the sample of Eudragit ${ }^{\circledR}$ RL100 and Eudragit ${ }^{\circledR}$ RS100.

\section{REFERENCES}

1. Sriamornsak P, Thirawong N, Puttipipatkhachorn S. Morphology and buoyancy of oil-entrapped calcium pectinate gel beads. AAPS J. 2004;6(3):65-71. doi:10.1208/aapsj060324.

2. Bardonnet PL, Faivre V, Pugh WJ, Piffaretti JC, Falson F. Gastroretentive dosage forms: overview and special case of Helicobacter pylori. J Control Release. 2006;111(1-2):1-18. doi:10.1016/j.jconrel.2005.10.031.

3. Pawar VK, Kansal S, Garg G, Awasthi R, Singodia D, Kulkarni GT. Gastroretentive dosage forms: a review with special emphasis on floating drug delivery systems. Drug Deliv. 2011;18(2):97110. doi:10.3109/10717544.2010.520354.

4. Hardenia SS, Jain A, Patel R, Kaushal A. Floating drug delivery systems: a review. Asian J Pharm Life Sci. 2011;1(3):284-93.

5. Singh BN, Kim KH. Floating drug delivery systems: an approach to oral controlled drug delivery via gastric retention. J Control Release. 2000;63(3):235-59. doi:10.1016/S0168-3659(99)00204-7.

6. Oh T-O, Kim J-Y, Ha J-M, Chi S-C, Rhee Y-S, Park C-W, et al. Preparation of highly porous gastroretentive metformin tablets using a sublimation method. Eur J Pharm Biopharm. 2013;83(3):460-7. doi:10.1016/j.ejpb.2012.11.009.

7. Sungthongjeen S, Sriamornsak P, Puttipipatkhachorn S. Design and evaluation of floating multi-layer coated tablets based on gas formation. Eur J Pharm Biopharm. 2008;69(1):255-63. doi:10.1016/j.ejpb.2007.09.013.

8. United States Pharmacopeia 32 and National Formulary 27, Rockville, MD: United States Pharmacopeial Convention, 2009.

9. de Oliveira MA, Yoshida MI, Silva DC. Quality evaluation of pharmaceutical formulations containing hydrochlorothiazide. Molecules. 2014;19(10):16824-36. doi:10.3390/ molecules191016824.

10. Meng L, Burris S, Bui H, Pan W-P. Development of an analytical method for distinguishing ammonium bicarbonate from the products of an aqueous ammonia $\mathrm{CO}_{2}$ scrubber. Anal Chem. 2005;77(18):5947-52. doi:10.1021/ac050422x.

11. Abbaspour MR, Sadeghi F, Garekani HA. Preparation and characterization of ibuprofen pellets based on Eudragit RS PO and RL PO or their combination. Int J Pharm. 2005;303(1-2):88-94. doi:10.1016/j.ijpharm.2005.07.016.

12. Müller J, Brock D, Knop K, Axel Zeitler J, Kleinebudde P. Prediction of dissolution time and coating thickness of sustained release formulations using Raman spectroscopy and terahertz pulsed imaging. Eur J Pharm Biopharm. 2012;80(3):690-7. doi:10.1016/j.ejpb.2011.12.003.

13. Locs J, Zalite V, Berzina-Cimdina L, Sokolova M. Ammonium hydrogen carbonate provided viscous slurry foaming-a novel technology for the preparation of porous ceramics. J Eur Ceram Soc. 2013;33(15-16):3437-43. doi:10.1016/ j.jeurceramsoc.2013.06.010.

14. Tunón A, Gråsjö J, Alderborn G. Effect of intragranular porosity on compression behaviour of and drug release from reservoir pellets. Eur J Pharm Sci. 2003;19(5):333-44. doi:10.1016/S09280987(03)00106-4.

15. Azarmi S, Farid J, Nokhodchi A, Bahari-Saravi SM, Valizadeh H. Thermal treating as a tool for sustained release of indomethacin from Eudragit RS and RL matrices. Int J Pharm. 2002;246(12):171-7. doi:10.1016/S0378-5173(02)00378-2. 